\title{
Uma Arquitetura Pedagógica para aprendizagem de matemática baseada na Teoria dos Campos Conceituais
}

\author{
Genilson Gomes Corradi ${ }^{1}$, Crediné S. de Menezes ${ }^{1,2}$ \\ ${ }^{1}$ Universidade Federal do Espírito Santo (UFES) - Programa de Pós-graduação em \\ Informática - Vitória - ES \\ ${ }^{2}$ Universidade Federal do Rio Grande do Sul (UFRGS) - Programa de Pós-graduação \\ em Informática na Educação - Av Paulo Gama, 110, Farroupilha, Porto Alegre - RS \\ \{ggcorradi, credine\}@gmail.com
}

\begin{abstract}
Researches of evaluation about learning has shown that students, at the beginning of their student life, have a great deal of difficulty in learning the contents of the subject of mathematics, especially the basic operations of addition/ subtraction and multiplication / division. In the Theory of Conceptual Fields, created by the French researcher Gérard Vergnaud, two pedagogical approaches are proposed to facilitate the learning of these operations, but their use is a difficult task for teachers. This work investigates these difficulties with teachers of a teaching network and proposes a Pedagogical Architeture to strengthening the learning of addition/subtraction and multiplication/division operations.
\end{abstract}

Resumo. As pesquisas de avaliação da aprendizagem tem mostrado que os alunos, no início da sua vida estudantil, tem muita dificuldade na aprendizagem dos conteúdos da disciplina de matemática, em especial, das operações básicas de soma/subtração e multiplicação/divisão. Na Teoria dos Campos Conceituais, criada pelo pesquisador Francês Gérard Vergnaud são propostas duas abordagens pedagógicas para facilitar a aprendizagem destas operações, porém a sua utilização é uma tarefa difícil para os professores. Este trabalho investiga estas dificuldades junto a professores de uma rede de ensino e propõe uma Arquitetura Pedagógica para potencializar a aprendizagem das operações de adição/subtração e multiplicação/divisão.

\section{Introdução}

O ensino da matemática sempre se apresentou como um grande desafio, fato comprovado pelas pesquisas de avaliação da aprendizagem como o SAEB (Sistema de Avaliação da Educação Básica) de 2017, principal intrumento de avaliação da Educação Básica. Esta pesquisa identificou que somente $\mathbf{7 , 3 \%}$ dos alunos atingem aprendizado adequado em matemática no ensino médio quando a meta era 40,6. O índice é ainda menor quando consideradas apenas as escolas públicas, onde apenas $\mathbf{3 , 6 \%}$ têm aprendizado adequado, o que significa que $\mathbf{9 6 , 4 \%}$ não aprendem o esperado na escola.

Em matemática alguns conteúdos são fundamentais e o domínio deles pode abrir portas para a aprendizagem de muitos outros. Dentre estes conteúdos, encontra-se o conceito das operações básicas de adição/subtração e multiplicação/divisão. Estas operações geralmente são ensinadas usando os métodos tradicionais que enfatizam apenas a memorização das operações e a aplicação do algoritmo de cálculo. 
Uma nova forma de ensinar matemática para as operações de adição/subtração e multiplicação/divisão, baseada na Teoria dos Campos Conceituais [Vergnaud, 1982], foi proposta pelo pesquisador francês Gérard Vergnaud. Para o ensino de adição e subtração ele criou uma abordagem pedagógica chamada Campo Aditivo e para o ensino da multiplicação/divisão, outra chamada Campo Multiplicativo. Estes dois campos já são utilizados por várias redes de ensino no Brasil que usam materiais concretos (figurinhas, bolas de gudes, etc) para auxiliar os alunos no processo de contagem para a resolução das situações-problemas. Entretanto, em função do grande número de alunos nas salas de aula e por se tratar de uma abordagem que exige mais do professor (colecionar situações-problemas, preparar listas de exercícios com as situações-problemas, aplicar individualmente as listas aos alunos, discutir as diferentes soluções dadas pelos alunos às situações-problemas, etc), é constatado que ele nem sempre consegue dar atenção individualizada e personalizada aos alunos, o que dificulta um trabalho eficiente com estas abordagens. Uma forma de minimizar esta dificuldade é criar uma rede onde os alunos possam colaborar/cooperar entre si na aprendizagem mediado pelo professor.

Considerando que a Teoria dos Campos Conceituais pressupõe liberdade da forma de resolução de uma situação-problema e esta pode ter mais de uma forma de resolução, isso se encaixa bem nos pressupostos de Arquiteturas Pedagógicas que são o de autonomia dos alunos na construção de conhecimento e de colaboração/cooperação dos entendimentos que cada um teve no processo individual de construção.

Dentro deste contexto, este artigo propõe uma Arquitetura Pedagógica com um suporte computacional para potencializar o processo de ensino e aprendizagem das 4 operações básicas da matemática baseada na Teoria dos Campos Conceituais, estimulando uma atitude protagonista dos alunos e mediada pelo professor. O suporte computacional proposto tem como principais características facilitar a colaboração entre alunos e professores e ser ubíqua.

Esse artigo está organizado em quatro seções. Além desta seção, onde o assunto é introduzido, na segunda é apresentada a fundamentação teórica, na terceira é descrita a arquitetura pedagógica e o suporte computacional proposto e na quarta seção são apresentadas as considerações finais.

\section{Fundamentação teórica}

A Arquitetura Pedagógica proposta neste trabalho se baseia na aplicação da Teoria dos Campos Conceituais com um suporte computacional como facilitador do ensino de matemática.

\subsection{Teoria dos Campos Conceituais}

Na década de 80, o pesquisador Francês Gérard Vergnaud, reconhecido especialista na Didática da Matemática, criou uma teoria epistemológica cognitivista chamada "Teoria dos Campos Conceituais". Vergnaud afirma que é praticamente impossível estudar os conceitos separadamente e, por isso, é preciso fazer recortes. Um exemplo na matemática é que não se deve ensinar adição separado de subtração, e nem multiplicação dissociada da divisão, pois estas operações possuem um forte relacionamento. Assim, os Campos Conceituais são unidades de estudo mais 
VIII Congresso Brasileiro de Informática na Educação (CBIE 2019)

Anais dos Workshops do VIII Congresso Brasileiro de Informática na Educação (WCBIE 2019)

promissoras, capazes de dar sentido aos problemas e às observações feitas em relação à conceitualização. Para Vergnaud, um campo conceitual significa:

“[...] um conjunto informal e heterogêneo de problemas, situações, conceitos, relações, conteúdos e operações de pensamento, conectados uns aos outros e, provavelmente, interligados durante o processo de aquisição." [VERGNAUD, 1982, p. 40] (tradução nossa).

Quanto à aplicação desta abordagem, (Santana, Alves e Nunes, 2015) afirmam:

\begin{abstract}
"Os processos cognitivos e as respostas dadas pelo sujeito são funções das situações com as quais é confrontado. Essas ideias significam que, em cada Campo Conceitual, existe uma grande variedade de situações e os conhecimentos dos estudantes são moldados pelas situações que, progressivamente, vão dominando. Dessa forma, são as situações que dão sentido aos conceitos, tornando-se o ponto de entrada para um dado Campo Conceitual."
\end{abstract}

A descoberta de novos conceitos, pelas crianças, é fruto do contato com situações diversificadas. O conceito é considerado como um conjunto de invariantes que os estudantes utilizam na ação ou também como uma terna de três conjuntos $\mathrm{C}=(\mathrm{S}, \mathrm{I}$, $\mathrm{R}$ ), em que: S: conjunto das situações que dão sentido ao conceito (a referência); I: conjunto das invariantes nas quais assenta a operacionalidade dos esquemas (o significado); R: conjunto das formas pertencentes e não pertencentes à linguagem que permitem representar simbolicamente o conceito, as suas propriedades, as situações e os procedimentos de tratamento (o significante) [Vergnaud, 1996]. Em cada situação está presente uma gama de conceitos e é importante que o professor proponha ao aluno diversas situações a serem resolvidas, pois, com isso, é possível que ele reconheça e manipule os invariantes operatórios e faça uso das representações simbólicas. Dessa forma, o contato com uma variedade de situações permite que o aluno dê sentido aos conhecimentos matemáticos que surgem de situações com distintos significados [Arrais, 2006].

A Teoria dos Campos Conceituais pode ser aplicada a vários domínios de conhecimento, mas o pesquisador atuou mais fortemente na identificação de campos conceituais relacionados à matemática. Na matemática os campos conceituais definidos pelo Vergnaud são o Campo Aditivo, que trata das operações de adição e subtração, e o Campo Multiplicativo, que trata da divisão e multiplicação.

Em [Cardoso et al, 2018] e [Brasil, 2014] é demonstrado que o ensino das operações básicas da matemática baseada na utilização dos Campos Aditivo e Multiplicativo vem contribuindo para a melhoria da aprendizagem. Em [Brasil, 2014] o MEC propõe orientação aos professores no uso destes campos. Isso demonstra a aceitação da eficácia desta teoria no ensino da matemática.

\title{
2.1.1 Campo Aditivo
}

Para o Campo Aditivo (ou Estrutura Aditiva), Vergnaud identificou 6 categorias, também chamadas de relações de base, a partir das quais é possível classificar todos os problemas de adição e subtração:

Composição: juntar partes para se obter o todo ou subtrair uma parte do todo para se obter a outra parte. Exemplo: Na gaveta tem seis balas de chocolate, três de hortelã e quatro de morango. Quantas balas tem na gaveta?

Transformação: situações que são caracterizadas por um estado inicial que sofrem uma transformação (com perda ou ganho) e resultam no estado final. Exemplo: Maria tinha $\mathrm{R} \$ 12,00$ e comprou uma boneca por $\mathrm{R} \$ 4,00$. Com quantos reais Maria ficou? 
VIII Congresso Brasileiro de Informática na Educação (CBIE 2019)

Anais dos Workshops do VIII Congresso Brasileiro de Informática na Educação (WCBIE 2019)

Comparação: são situações nas quais é estabelecida uma relação entre duas quantidades, uma denominada de referente e a outra de referido. Exemplo: Carlos tem cinco anos. Taís tem sete anos a mais que ele. Quantos anos tem Taís?

Composição de duas transformações: problemas referentes às situações em que são dadas duas transformações e, por meio de uma composição dessas duas, se determina a terceira transformação. Exemplo: José tem livros de histórias infantis. Ele ganhou cinco livros de seu pai e quatro livros de sua tia. José resolveu dar três dos seus livros mais velhos para seu amigo Jonas. Descontando os livros que José deu, em quanto aumentou a quantidade de livros de José?

Transformação de uma relação: são situações nas quais é dada uma relação estática e se busca uma nova, que é gerada a partir da transformação da relação estática dada. Exemplo: Saulo devia R \$ 8,00 a Glebson, pagou R \$ 5,00. Quanto ele deve agora?

Composição de relações estáticas: duas ou mais relações estáticas se compõem para dar lugar a outra relação estática. Exemplo: Ana deve quatro figurinhas a Bete, três a Cris e seis a Mara. Quantas figurinhas Ana deve ao todo?

\subsubsection{Campo Multiplicativo}

O Campo Multiplicativo (ou Estrutura Multiplicativa), que possui uma dimensão de conceito muito mais amplo do que os conceitos do Campo Aditivo, abrange diversos conceitos, dentre eles podemos citar: dobro, metade, triplo, fração, funções lineares e não lineares, razão, taxa, proporção, espaço vetorial, isomorfismo, combinação, produto cartesiano, área, volume. [Vergnaud, 2009] agrupa estes conceitos em duas grandes categorias: o Isomorfismo de Medidas e o Produto de Medidas.

Esse campo está dividido em duas relações: ternária (relacionada ao Isomorfismo de Medidas) e quaternária (relacionada ao Produto de Medidas). Estas relações são mostradas no esquema elaborado por Magina, Santos e Merlini [Magina, 2014] apresentados na Figura 1.

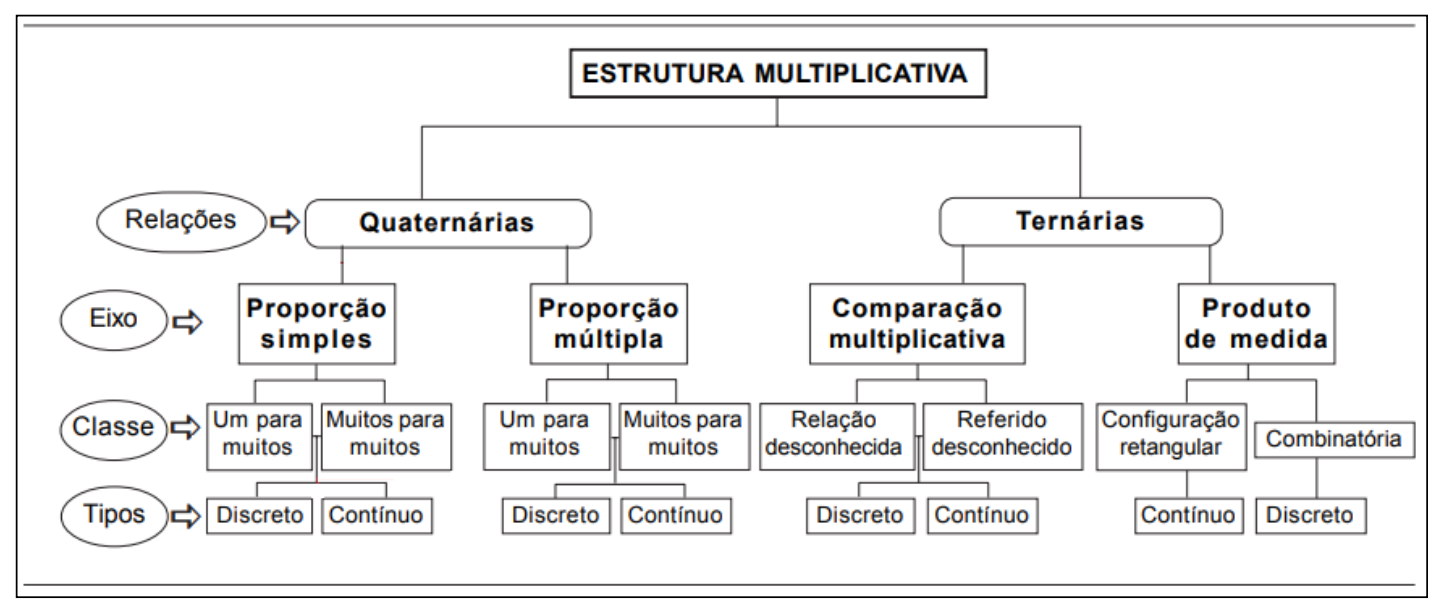

Figura 1: Esquema do Campo Multiplicativo

Fonte: Magina, Santos e Merlini, 2014. 
VIII Congresso Brasileiro de Informática na Educação (CBIE 2019)

Anais dos Workshops do VIII Congresso Brasileiro de Informática na Educação (WCBIE 2019)

No grupo Isomorfismo de Medidas estão os problemas elementares que estabelecem relações proporcionais simples entre conjuntos de mesma cardinalidade (objetos do mundo real). Vergnaud descreve nesse grupo um grande número de situações, dentre os quais estão os problemas de multiplicação, divisão e regra de três simples. São exemplos de situações-problemas desta categoria:

Exemplo 1: Para uma festa foram levados 68 doces. Considerando que cada convidado levou 4 doces, quantas pessoas foram convidadas? (classe: um para muitos)

Exemplo 2: Sabe-se que 12 meninos possuem juntos 72 carrinhos. Considerando que cada menino tenha a mesma quantidade de carrinhos, quantos meninos seriam se o total de carrinhos fosse 138? (classe: muitos para muitos)

Já no grupo Produto de Medidas estão as situações que envolvem configuração retangular ou as que requerem o uso de raciocínio combinatório, onde todos os elementos de um grupo estão relacionados com todos os elementos do outro grupo. Para Vergnaud, a essa categoria pertence uma relação ternária entre três quantidades, em que uma consiste no produto das outras duas. São exemplos de situações-problemas desta categoria:

Exemplo 1: Em uma caixa retangular cabem 48 de bombons. Sabendo que os bombons estão organizados em fileiras e que em cada fileira cabem 8 bombons, quantas fileiras de bombons há nessa caixa?

Exemplo 2: Uma lanchonete oferece os seguintes sabores de suco: laranja, uva, abacaxi e morango. Oferece também os seguintes tipos de sanduíche: misto quente, x-salada e bauru. Quantas diferentes combinações de sucos e sanduiches pode pedir um cliente?

\subsection{Arquiteturas Pedagógicas}

A educação vem se apropriando das tecnologias digitais principalmente para aperfeiçoar e facilitar o entendimento do aluno e permitir aos professores ampliar o seu atendimento sem aumento do seu tempo de atuação.

Com isso, houve uma mudança no próprio instrumento de uso pelo professor em sala de aula, passando de um quadro branco, com um pincel, para computadores, softwares, dispositivos móveis, etc.

Porém, o uso das tecnologias digitais na educação sem uma boa estruturação não gera o efeito desejado de melhorar a aprendizagem, ou seja, a tecnologia pela tecnologia não gera resultado significativo.

A combinação de abordagens pedagógicas com o uso das tecnologias digitais, em especial a internet e inteligência artificial, com o objetivo de potencializar a aprendizagem e dando autonomia aos alunos são estruturas de aprendizagem chamada de Arquitetura Pedagógica (AP).

Numa AP o conhecimento acontece através das interações entre os sujeitos e o meio. Os alunos tem o papel mais protagonista e cooperam entre si na busca do conhecimento enquanto o professor atua como mediador. E neste contexto, a computação ubíqua onde o tempo e o espaço são definidos por cada indivíduo, tem sido um grande alavancador na construção de suportes computacionais para as APs (CastroJr e Menezes, 2011). 
VIII Congresso Brasileiro de Informática na Educação (CBIE 2019)

Anais dos Workshops do VIII Congresso Brasileiro de Informática na Educação (WCBIE 2019)

\section{Arquitetura Pedagógica e suporte computacional proposto}

Nesta seção descreveremos a AP proposta, o suporte computacional concebido para ela e comentaremos sobre o protótipo e o experimento realizado em duas escolas.

\subsection{Arquitetura Pedagógica proposta}

A concepção da AP aqui apresentada é parte de um projeto junto a uma rede municipal de ensino, do qual participam professores da rede. Foram realizados levantamentos com estes professores para entender suas dificuldades na aplicação do Campo Aditivo e Multiplicativo na forma tradicional e sem o uso de tecnologia digital.

Dentre as dificuldades informadas pelos professores, relacionadas ao processo de ensino das operações de adição/subtração e multiplicação/divisão usando o Campo Aditivo e o Campo Multiplicativo sem o apoio computacional, citamos as principais:

1. A quantidade das situações-problemas é pequena devido os professores utilizarem basicamente as do livro texto. Na necessidade de reaplicar uma sessão de exercícios para alunos que não conseguiram acertar, acaba-se repetindo as mesmas situaçõesproblemas o que gera desinteresse do aluno e/ou não explora o seu potencial;

2. Trabalhar com papel e lápis ou mesmo com um kit de objetos reais (figurinhas, bolinhas, etc) para auxiliar no processo de contagem, considerando que são cerca de 20 alunos por turma, dificulta o professor conseguir ver como cada aluno está desenvolvendo ou desenvolveu a sua solução;

3. A correção da resolução das situações-problemas em toda a sua extensão (resposta, desenvolvimento e processo de contagem) por ficar muito onerosa para os professores que acabam priorizando somente a correção da resposta;

4. O processo de fornecer dicas para os alunos é complicado, pois pressupõe que o professor vistorie manualmente solução de cada aluno, o que em função da quantidade de alunos nem sempre é possível;

5. Os alunos desta geração conectada não conseguem manter-se concentrados com resolução de problemas usando papel e lápis, coisa que a tecnologia digital muito contribui pela possibilidade de gerar um ambiente atrativo e lúdico. Além do que a a atividade de socialização dos resultados entre eles gera certo tumulto no espaço escolar.

A AP definida tem as seguintes etapas:

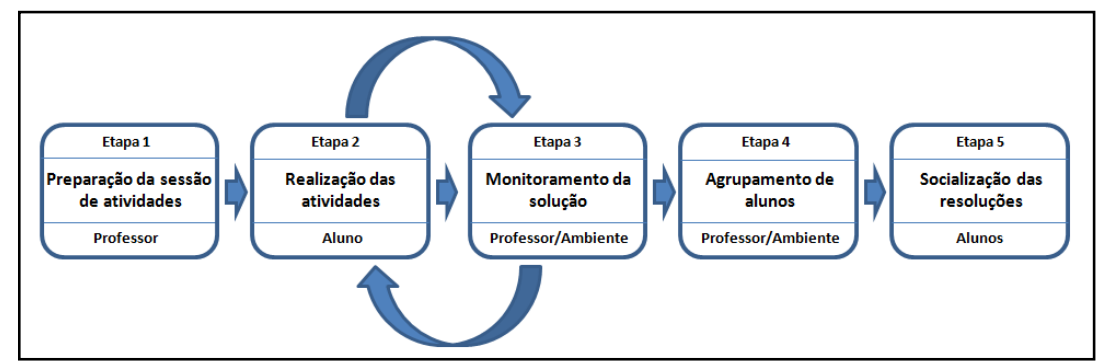

Figura 2: Fluxo simplificado da Arquitetura Pedagógica proposta Fonte: Autores

Etapa 1: Professor prepara sessão de atividades para os alunos - Nesta etapa o professor define as situações-problemas referentes aos Campos Aditivos e Multiplicativos e gera a sessão de exercícios para os alunos que pode ser única para todos os alunos ou diferenciada por aluno. 
VIII Congresso Brasileiro de Informática na Educação (CBIE 2019)

Anais dos Workshops do VIII Congresso Brasileiro de Informática na Educação (WCBIE 2019)

Etapa 2: Alunos resolvem individualmente as atividades - Nesta etapa, cada aluno revolve individualmente as atividades definidas para ele, registrando além da resposta qual foi a estratégia de resolução (raciocínio lógico e aritmético usado). Todo o rastro da resolução é registrado no ambiente digital.

Etapa 3: Professor monitora resolução - Nesta etapa, o professor é notificado pelo ambiente digital se determinado aluno está indo por um caminho de solução que não gerará a resposta correta. Ele poderá fazer um atendimento local ou enviar uma notificação para o aluno com uma dica para que ele possa reestruturar o caminho da solução. Esta mesma ação poderá ser feita pelo ambiente digital (opção configurada pelo professor) que ofertará dicas de solução para os alunos.

Etapa 4: Identificação de agrupamento de resoluções - Nesta etapa, com base em critérios definidos (quantidade máxima de alunos por grupo, configuração do grupo, etc) o ambiente digital define grupos de alunos com formas de resolução diferente (a resposta pode estar certa ou errada) para a socialização de suas formas de resolução. $O$ professor poderá mudar a formação do grupo definido pelo ambiente, caso deseje.

Etapa 5: Socialização das resoluções pelos alunos - Nesta etapa, os alunos agrupados dialogam sobre as diferentes formas de resolver as situações-problemas buscando identificar outras possibilidades de resolução ou o surgimento de outras formas de resolução para uma mesma situação-problema. A idéia principal é permitir que cada aluno conheça a diversidade de resoluções, expandindo seu conhecimento sobre o tema. É nesta etapa que ocorre a grande profusão de conhecimento pelos alunos mediado pelo professor.

\subsection{Suporte computacional para a Arquitetura Pedagógica proposta}

Para definição do suporte computacional à AP (ambiente digital), inicialmente identificamos seus participantes (atores) com seus papéis na arquitetura e os requisitos (funcionais e não funcionais). Assim, dentro do contexto analisado, observamos a existência de três classes diferentes de atores: os alunos, os professores e agentes inteligentes. Os papéis identificados para cada ator são apresentados na Tabela 1.

Tabela 1: Atores e seus papéis na Arquitetura Pedagógica proposta Fonte: Autores

\begin{tabular}{|c|c|}
\hline Ator/Participante da AP & Papel \\
\hline \multirow{4}{*}{ Aluno } & 1. Resolver as situaçôes-problemas definidas pelo professor \\
\hline & 2. Apresentar sua forma de resolução aos alunos do seu grupo \\
\hline & 3. Apoiar os alunos do seu grupo que não conseguiram a resposta correta \\
\hline & 4. Refazer a resolução da situação-problema, caso não tenha conseguindo resolver ou resposta incorreta \\
\hline \multirow{6}{*}{ Professor } & $\begin{array}{l}\text { 1. Cadastrar as configurações gerais para suporte à geração das situações-problemas do campo aditivo e } \\
\text { multiplicativo pelo ambiente digital }\end{array}$ \\
\hline & $\begin{array}{l}\text { 2. Executar no ambiente digital a geração das situações-problemas do campo aditivo e multiplicativo, } \\
\text { cadastrando para cada situação-problema as respostas prováveis e dicas de resolução }\end{array}$ \\
\hline & 3. Gerar a sessão de atividades contendo situações-problemas do campo aditivo e/ou do multiplicativo \\
\hline & 4. Monitorar a resolução pelos alunos, intervindo, caso necessário \\
\hline & 5. Ajustar os agrupamentos de alunos, caso necessário \\
\hline & 6. Configurar os recursos de geração de notificação e de agrupamento de alunos \\
\hline \multirow{5}{*}{ Agente Inteligente } & $\begin{array}{l}\text { 1. Notificar o professor quando a resolução do aluno estiver indo por um caminho que não chegará à } \\
\text { solução correta }\end{array}$ \\
\hline & 2. Ofertar dica para o aluno quando necessário \\
\hline & 3. Gerar os agrupamentos de alunos para socialização da forma de resolução \\
\hline & 4. Fazer a correção automática das resoluções dos alunos segundo os critérios definidos \\
\hline & $\begin{array}{l}\text { 5. Gerar mapa de progresso da aprendizagem do aluno (individual x coletivo para cada sessão de } \\
\text { atividades) }\end{array}$ \\
\hline
\end{tabular}

Na Tabela 2 são apresentados os requisitos funcionais e na Tabela 3 os requisitos não funcionais que deverá ter o ambiente digital para suportar a AP. 
VIII Congresso Brasileiro de Informática na Educação (CBIE 2019)

Anais dos Workshops do VIII Congresso Brasileiro de Informática na Educação (WCBIE 2019)

Tabela 2: Requisitos funcionais da AP proposta

Fonte: Autores

\begin{tabular}{|c|}
\hline Requisitos Funcionais \\
\hline $\begin{array}{l}\text { 1. O ambiente deverá permitir que os professores registrem todos os dados de suporte para geração das } \\
\text { situações-problemas (temas, personagens, etc); }\end{array}$ \\
\hline $\begin{array}{l}\text { 2. O ambiente deverá permitir o registro das relações do campo aditivo e multiplicativo com informações } \\
\text { para facilitar a geração das situações-problemas; }\end{array}$ \\
\hline $\begin{array}{l}\text { 3. O ambiente gerará as situações-problemas para o campo aditivo e multiplicativo, com inteligência para } \\
\text { não repetir enunciados; }\end{array}$ \\
\hline $\begin{array}{l}\text { 4. O ambiente deverá permitir que os professores registrem a resposta certa e as prováveis para cada } \\
\text { situação-problema gerada; }\end{array}$ \\
\hline $\begin{array}{l}\text { 5. O ambiente deverá permitir que sẹjam geradas sessões de atividades para o campo aditivo e } \\
\text { multiplicativo configurados para um aluno ou um grupo de alunos e por tipo de relação ou categorias; }\end{array}$ \\
\hline $\begin{array}{l}\text { 6. O ambiente deverá permitir que cada aluno resolva as situações compostas nas sessões de atividade } \\
\text { configuradas pelo professor; }\end{array}$ \\
\hline $\begin{array}{l}\text { 7. O ambiente deverá ter um recurso gráfico para auxiliar os alunos no processo de contagem (palitos, } \\
\text { figura, bolinhas) para resolução das situações; }\end{array}$ \\
\hline $\begin{array}{l}\text { 8. O ambiente deverá permitir configurar as situações-problemas por complexidade de acordo com a } \\
\text { idade/série dos alunos; }\end{array}$ \\
\hline $\begin{array}{l}\text { 9. O ambiente deverá registrar o log das resoluções (rastro) das sessões de atividades que foram geradas } \\
\text { para os alunos; }\end{array}$ \\
\hline $\begin{array}{l}10.0 \text { ambiente deverá permitir que o professor ofereça dica para auxiliar os alunos com dificuldade na } \\
\text { resolução das situações-problemas; }\end{array}$ \\
\hline $\begin{array}{l}\text { 11. O ambiente deverá permitir que o professor configure as regras para notificação ao aluno sobre dicas } \\
\text { e de agrupamentos de alunos para colaboração entre alunos; }\end{array}$ \\
\hline $\begin{array}{l}\text { 12. } 0 \text { ambiente deverá gerar o mapa de progresso de aprendizagem do aluno comparando a atividade } \\
\text { individual e coletiva e também das várias sessões que foram propostas; }\end{array}$ \\
\hline $\begin{array}{l}\text { 13. O ambiente deverá corrigir as resoluções identificando o estilo de aprendizagem baseado no rastro } \\
\text { deixado pelo aluno na resolução das situações-problema; }\end{array}$ \\
\hline
\end{tabular}

Tabela 3: Requisitos funcionais da AP proposta

Fonte: Autores

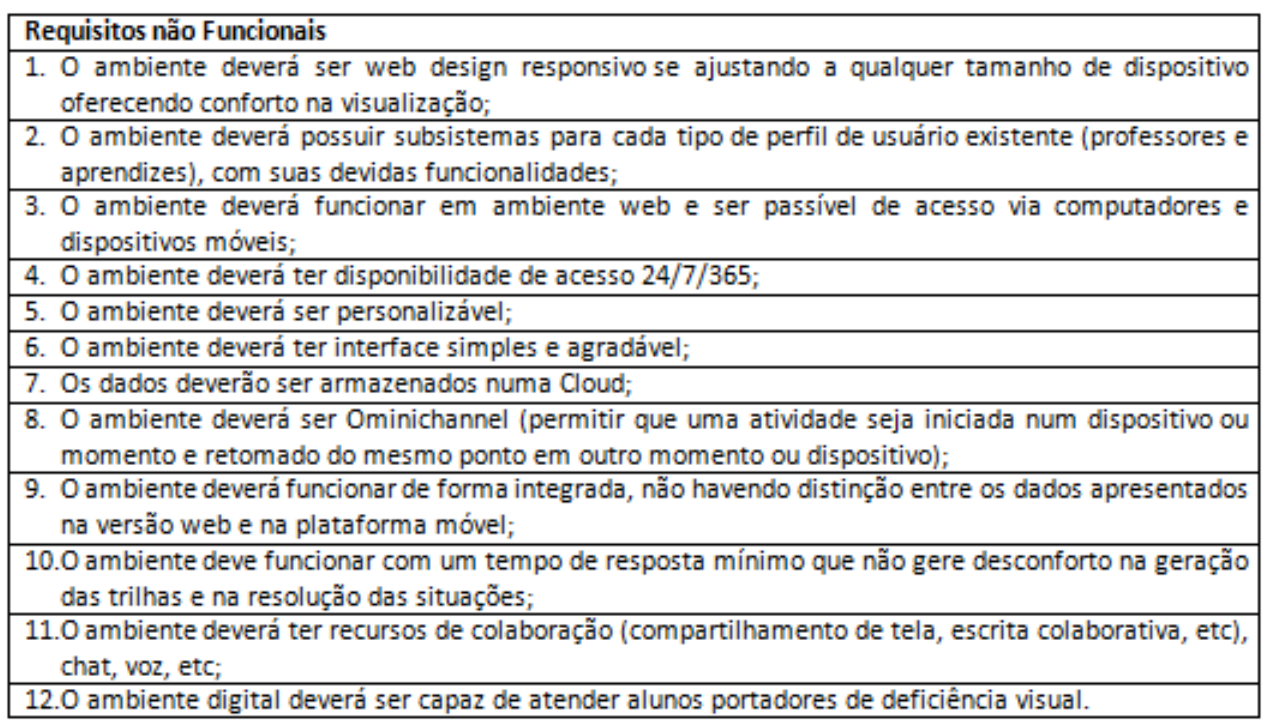

\subsection{Construção de um protótipo}

Para validar o objetivo do ambiente digital proposto, foi construido um protótipo (recorte com parte dos requisitos para Campo Aditivo) usando ferramentas tecnológicas atuais que roda em ambiente web numa cloud. Das funcionalidades construídas no protótipo, destacamos:

Gerador de Situações-Problemas: Possibilita que o professor crie situações-problemas que serão selecionadas pela funcionalidade de geração de sessão. 
VIII Congresso Brasileiro de Informática na Educação (CBIE 2019)

Anais dos Workshops do VIII Congresso Brasileiro de Informática na Educação (WCBIE 2019)

Gerador de Sessão de Exercícios: Permite a geração da sessão de exercícios que pode ser igual para todos os alunos da turma ou diferenciado por aluno ou grupo de alunos. $\mathrm{O}$ professor também seleciona quantas situações-problemas de cada relação aditiva ele quer na sessão. Possui mecanismo para não gerar numa mesma sessão de exercícios, situações-problemas com o mesmo modelo de resolução (pré-frase).

Resolução de Situação-Problema: Exibe para o aluno todas as situações-problemas que ele necessita resolver. Possui recurso gráfico para auxiliar os alunos no processo de contagem semelhante quando fazem usando objetos concretos. Na figura 3 , a tela desta funcionalidade é mostrada.

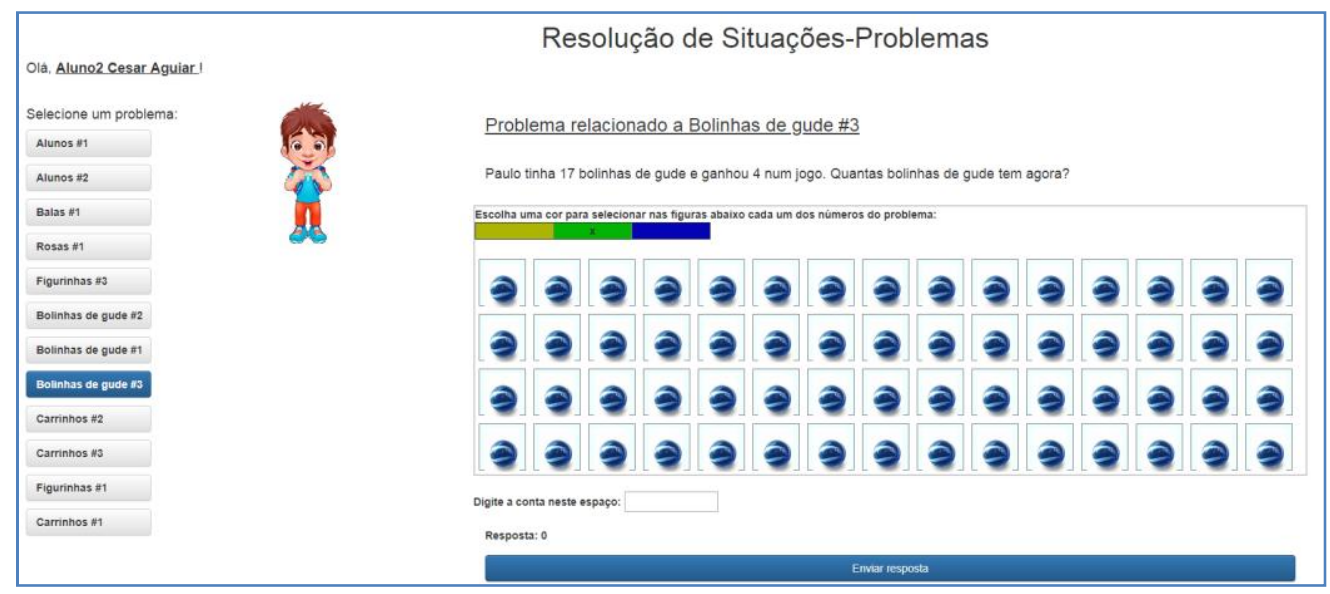

Figura 3: Resolução de situações-problemas do Campo Aditivo. Fonte: Autores

Análise dos resultados da sessão: O protótipo fornece consultas que permitem que o professor monitore o processo de resolução das sessões de exercícios pelos alunos e compreenda suas dificuldades, podendo ser mais eficaz em suas ações pedagógicas.

O protótipo foi construído como uma aplicação cliente-servidor na internet, usando a arquitetura MVC. O sistema foi implementado em Python, banco de dados SQLITE3 para armazenamento dos dados, ferramenta SQLAlchemy (ORM) para persistência de banco de dados, framework FLASK para geração de aplicações WEB e o framework Javascript Bootstrap para padronização da parte de interface. A hospedagem foi feita no PythonAnywhere.

\subsection{Validação da Proposta}

Foi realizado um experimento em duas escolas de uma rede municipal em 3 turmas do ensino fundamental séries iniciais onde os alunos foram submetidos a uma sessão de exercícios em papel com 16 situações-problemas do campo aditivo contemplando as relações aditivas de Composição, Transformação e Comparação.

A correção foi feita segundo critérios definidos pelo pesquisador. Os alunos foram submetidos, no ambiente digital prototipado a similar sessão de exercícios (mesma quantidade e complexidade das situações-problemas). A ferramenta fez a correção segundo os mesmos critérios anteriores. Os resultados das duas aplicações foram comparados donde se concluiu que o suporte computacional melhorou a aprendizagem cerca de 11\% (onze por cento), sendo que os agrupamentos das diferentes formas de resolução para a colaboração/cooperação entre os alunos foi feita de forma manual (definida pelo professor) e de forma resumida. 
VIII Congresso Brasileiro de Informática na Educação (CBIE 2019)

Anais dos Workshops do VIII Congresso Brasileiro de Informática na Educação (WCBIE 2019)

Os professores responderam um questionário sobre $\mathrm{o}$ experimento $\mathrm{e} a$ importância da AP na sua atividade de ensino do tema aqui tratado.

\section{Considerações Finais}

Com base nos resultados das aplicações com os alunos e nas respostas do questionário aplicado aos professores, ficou evidenciado que a AP proposta minimiza as dificuldades elencadas na aplicação da TCC. Os professores elogiaram no ambiente a possibilidade de geração de sessões de exercícios específicas para alunos com base no resultado das sessões anteriores, a correção automática com o rastro do raciocínio usado pelos alunos na resolução das situações-problemas e por permitir que eles tivessem uma visão das diferentes formas de resolução das situações-problemas, facilitando a formação dos grupos para a atividade de socialização do conhecimento.

Assim, entendemos que como trabalho futuro a construção deste ambiente digital para suportar a AP trará uma grande contribuição para o aumento proficiência dos alunos em matemática, melhorando os resultados nas pesquisas de avaliação de aprendizagem, em especial, do Ensino Fundamental.

\section{Referências}

Carvalho, M. J. S., R. A. Nevado, and C. S. Menezes. "Arquiteturas Pedagógicas para Educação a Distância: Concepções e Suporte Telemático. In XVI Simpósio Brasileiro de Informática na Educação." (2005): 351-360.

Castro-Jr, A., Menezes, C. (2011). Aprendizagem colaborativa com suporte computacional. In Pimentel, M. and Fuks, H., editors, Sistemas Colaborativos, chapter 9, pages 135-153. Ed. Campus: Rio de Janeiro

Cardoso, Valdinei Cezar, Rúbia Barcelos Amaral-Schio, and Samuel Rocha de Oliveira. "UM ESTUDO DE SITUAÇÕES-PROBLEMA DO CAMPO MULTIPLICATIVO EXPLORADAS POR PROFESSORES E ESTUDANTES DO ENSINO FUNDAMENTAL." Nuances: estudos sobre Educação 29.3 (2018).

Etcheverria, Teresa Cristina. O Ensino das Estruturas Aditivas junto a Professoras dos Anos Iniciais do Ensino Fundamental. 2014. 252 f. Diss. Tese (Doutorado em Educação Matemática, Área de concentração: Ensino e Aprendizagem em Matemática e suas Inovações)-Universidade Anhanguera de São Paulo, São Paulo, SP, 2014.

Santana, Eurivalda, Alex Andrade Alves, and Célia Barros Nunes. "A Teoria dos Campos Conceituais num Processo de Formação Continuada de Professores." Bolema: Boletim de Educação Matemática 29.53 (2015): 1162-1180.

Vergnaud, Gérard. "Psicología Cognitiva e do Desenvolvimento e Pesquisas em Educação Matemática: Algumas questões teóricas e metodológicas. Trad. de Weiss, J. Apresentação concedida para o grupo Canadense de Estudos em Educação Matemática na Queen'se University, Kingston, jun.1982.

. A Teoria dos Campos Conceituais. In: BRUN, J. Evolução das relações entre a Psicologia do Desenvolvimento Cognitivo e a Didática da Matemática. Editora: Instituto Piaget. Lisboa, 1996. 